\title{
IMAGENS DE SI: MULHERES FEMINISTAS NO CONTEXTO CONTEMPORÂNEO MIDIÁTICO
}

\author{
Nayara Iris Silva e Souza \\ Mestranda em Letras (Estudos da Linguagem) pela Universidade Federal de Ouro Preto \\ (UFOP) \\ nayara_iris@hotmail.com \\ Paulo Henrique Aguiar Mendes \\ Professor adjunto da Universidade Federal de Ouro Preto (UFOP) \\ pauloufop01@gmail.com
}

\section{RESUMO}

Os grupos minoritários se encontram, no decorrer da história, em desvantagem nas diversas facetas da vida social, visto que vivemos em uma sociedade patriarcal onde imperam ideais de masculinidade e feminilidade. Nesse contexto, buscamos compreender como mulheres feministas e militantes constroem espaços de resistência na plataforma on-line Facebook. Em especial, buscamos identificar e analisar as estratégias discursivas que são utilizadas pelas mulheres na busca de igualdade de gênero na sociedade. Esta pesquisa analisa 02 perfis individuais de figuras públicas do Facebook: Djamila Ribeiro e Márcia Tiburi. Por meio da Análise do Discurso, em especial a noção de ethos discursivo, com base no pensamento de Amossy (2005, 2018) e Charaudeau (2016), procuramos compreender como essa plataforma de propagação do discurso auxilia na construção da imagem da mulher contemporânea. É possível dizer, de modo a sintetizar, que as mulheres desempenham papel de ativas, desconstruindo as representações sociais fixas de mulher passiva.

Palavras-chave: Análise do Discurso; facebook; feminismo; ethos discursivo.

\begin{abstract}
Minority groups have been facing disadvantages in several aspects of social life throughout history, since we live in a patriarchal society where constructs of masculinity and femininity are predominant. In this context, we seek to understand how groups of feminist and militant women build spaces of resistance on social media platforms such as Facebook. Our goal is to identify and to analyze the discursive strategies used by women in the quest for gender equality in society. This research analyzes two individual profiles of public figures on Facebook: Djamila Ribeiro and Márcia Tiburi. Based on the principles of Discourse Analysis, the discussion of ethos is based on Amossy (2005, 2018) and Charaudeau (2016). We sought to understand how social media works as a platform for propagating discourse, thus assisting in the construction of new realities. In the cases approached in this paper, those realities regard issues revolving around women's identities and public image, as well as constructs of femininity. In short, one can say that Ribeiro and Tiburi, by performing the role of active women, deconstruct social representations of women as being passive.
\end{abstract}

Keywords: Discourse Analysis; facebook; feminism; discursive ethos. 


\section{Introdução}

Os grupos minoritários se encontram, no decorrer da história e ainda no século XXI, em desvantagem nas diversas facetas da vida social tais como financeira, educacional, política e relacionadas à área da saúde. Este trabalho dedica espaço às vozes feministas, em especial, busca por mulheres que se declaram militantes e que por meio da internet encontraram espaço de resistência.

Nesse contexto, a mulher atual busca ainda espaço para debate, participação na política e nas decisões públicas. Ambientes esses que são locais de informação, produção de conhecimento e compartilhamentos das experiências vividas, além de caracterizaremse como meios de denúncia de repressões sofridas no ambiente privado e social. A internet é uma importante ferramenta de comunicação que se encontra cada dia mais inserida na vida da população devido ao seu fácil acesso, seja através do celular, do tablet ou do notebook.

A Web 2.0 possibilitou a integração, em um mesmo espaço, de uma multiplicidade de pessoas, informações, culturas, crenças, imaginários sociais e ideologias. Esse acesso a tamanha diversidade corroborou o aumento da expressão da reflexividade. "Em particular, a linguagem da mídia de massa é detalhadamente analisada como um espaço de poder, de lutas, e também como um espaço onde a linguagem é aparentemente transparente" (WODAK, 2004, p. 231). Além disso, as ideologias e hegemonias são, na verdade, desestabilizadas pelo alto fluxo de informações, pela mobilidade constante de discursos e pessoas.

Pretendemos, nesta pesquisa, por meio das estratégias discursivas utilizadas pelas mulheres que se declaram feministas e militantes, identificar e analisar a construção do 
ethos da mulher contemporânea como resistência política. Os objetos discursivos são 02 (duas) páginas pessoais do Facebook: Djamila Ribeiro e Márcia Tiburi. O delineamento de tais objetivos levou em conta a concepção de linguagem que aponta para sua dimensão social. Quando se trata do contexto midiático, compreender os aspectos da vida social que implicam a desigualdade só se torna possível através da análise dos discursos.

\section{Estudos da linguagem}

A língua está intrinsecamente relacionada à vida social em sua totalidade; o que inclui os sujeitos participantes e as intenções dos envolvidos nas práticas cotidianas. 0 discurso é um modo de prática social (BRANDÃO, 2014) que não se constitui individualmente, mas resulta das práticas coletivas. Este, portanto, não é fixo, modifica-se de acordo com a interação entre grupos sociais e seus respectivos posicionamentos sóciohistóricos.

O discurso pode ser concebido como conjunto de práticas de linguagem que orientam e possibilitam a criação de enunciados específicos e a produção de sentidos. É através dele que a realização e a significação dos acontecimentos se manifestam. A enunciação (BENVENISTE, 2006) é um ato singular de produção e interpretação de um enunciado em circunstâncias históricas determinadas, o qual estabelece uma relação dialógica entre os interlocutores.

É por meio da linguagem que agimos em grupo, por isso a reconhecemos como forte instrumento de poder, atuando de maneira individual ou coletiva, dependendo do objetivo de quem enuncia. Maingueneau (1997) considera a linguagem uma forma de 
ação. Para o linguista "cada ato de fala (batizar, permitir, mas também prometer, afirmar, interrogar, etc.) é inseparável de uma instituição, aquela que este ato pressupõe pelo simples fato de ser realizado" (MAINGUENEAU, 1997. p. 29). O poder é relevante e importante para a construção e manutenção da estrutura social e seus diferentes estratos de dominação. Os grupos dominantes agem de acordo com seus interesses, e isso reflete na estrutura social e nas práticas cotidianas.

Para Charaudeau (2013, p. 65) “o mecanismo pelo qual se é legitimado é o reconhecimento de um sujeito por outros sujeitos, realizado em nome de um valor que é aceito por todos." Ainda, segundo o autor, esse ser de palavra é sempre duplo, pois é constituído por sua legitimidade enquanto ser social e ser discursivo, sendo assim, as duas se interpelam.

Além disso, a linguagem, bem como a enunciação, têm se mostrado fontes de poder nas relações sociais, pois são capazes de construir nossas identidades e também de reproduzir ou modificar nossa forma de organização social. Diante disso, pretendemos considerar de que maneira a linguagem se coloca no discurso, identificar sua voz para, então, descrever o ethos e observar através de quais estratégias o sujeito feminino se manifesta.

\section{0 ethos discursivo}

Todo ato de tomar a palavra implica a construção de uma imagem de si. Para tanto, não é necessário que o locutor faça seu autorretrato, detalhe suas qualidades nem mesmo que fale explicitamente de si. Seu estilo, suas competências linguísticas e enciclopédicas, suas crenças implícitas são suficientes para construir uma representação de sua pessoa. Assim, deliberadamente ou não, o locutor efetua em seu discurso uma apresentação de si (AMOSSY, 2018, p. 09). 
A atividade da argumentação objetiva, em linhas gerais, produz o efeito de persuasão. Desde Aristóteles, as provas retóricas se traduzem pelas categorias do ethos, do pathos e do logos, as quais se relacionam de forma integrada nas práticas discursivas. A dimensão do ethos está relacionada à imagem do orador; a dimensão do pathos se refere às emoções e afetos projetados no auditório, enquanto a dimensão do logos diz respeito à racionalidade dos argumentos constitutivos do próprio discurso. $\mathrm{O}$ orador, ao dizer algo, projeta uma imagem de si, que é considerada o seu ethos. "Não há, pois, ato de linguagem que não passe pela construção de uma imagem de si. Desde o instante em que se fala, aparece, transparece, emerge de si, uma parte do que se é através do que se diz" (CHARAUDEAU, 2016, p. 72). Vemos que "o ethos é uma imagem do autor, não o autor real; é um autor discursivo, um autor implícito" (FIORIN, 2015, p. 70). É a imagem que o autor constrói de si ao proferir um discurso. No entanto, para que a legitimidade do orador seja validada pela sua credibilidade, é necessário que o auditório as reconheça por meio do discurso.

Há diversas linhas de estudo do ethos, cada qual com características específicas das disciplinas que o abordam. Nesta pesquisa, analisa-se o ethos pelo viés da análise do discurso, especialmente de linha francesa, com vistas a estudar os discursos de mulheres feministas contemporâneas. Toda vez que o enunciador profere algo, constrói uma imagem de si e do auditório e, ao projetá-lo, define o que acredita ser melhor para convencê-lo do que se pretende.

Charaudeau (2016) aponta as condições de sinceridade, de saber e de desempenho como parte do ethos. O orador precisa viver do jeito que afirma em seus discursos, agir à maneira que prega no seu cotidiano e suas atitudes devem ser 
concomitantes com suas crenças. O orador e suas vozes estabelecem uma esfera de credibilidade, que é conferida por seus leitores ou seguidores; é fundamental que aja de acordo com seu discurso para que continue conferindo-lhe legitimidade.

Cada indivíduo, na situação de comunicação, é legitimado a ocupar determinados cargos e proferir certos discursos. A função social que o locutor desempenha na sociedade é de extrema importância para que seu discurso seja ou não legitimado pelo público alvo. "A eficácia da palavra não depende do que ela enuncia, mas daquele que a enuncia e do poder do qual ele está investido aos olhos do público" (AMOSSY, 2005, p. 121). Sendo assim, a enunciação é um ato implícito e explícito e aqueles nela envolvidos, nas suas relações com os outros, desenvolvem diversos papeis sociais e discursivos.

Acreditamos que a Análise do Discurso é um campo de estudos que pode contribuir para as questões que envolvem o feminismo em meios digitais. Ele revela a vontade e, até mesmo, uma necessidade de mudança na estrutura social que se instaurou. As novas mídias permitiram que novas vozes fossem ouvidas, ou, pelo menos, estabeleceram um lugar de fala para essas vozes que não podiam se manifestar. A liberdade que as mídias proporcionam traz à tona a "dualidade" de ideias; afinal há espaço para grupos que são, por diversas razões, discriminados na sociedade.

\section{3. $O$ feminismo e a rede on-line}

A emergência do movimento feminista ventilou a reflexão sobre a desigualdade implícita nos papéis de gênero socialmente impostos. Na sociedade, homens e mulheres nunca estiveram em situação de igualdade e isso não se restringe somente à realidade 
brasileirai, em que os homens ocupam cargos mais importantes e decisivos e a diferença salarial entre os sexos se comparada, em alguns setores, é alarmante.

Impossibilitadas de estudar, a mão de obra feminina era mais barata e o capitalismo se aproveitou para escravizá-las, e as desigualdades salariais se perpetuam até o século XXI, como também o preconceito de gênero em certas carreiras que foram historicamente definidas como masculinas ou femininas.

No cenário recente, o salário atual da mulher é inferior ao do homemii, e se trabalha fora de casa, na maioria dos casos, o trabalho doméstico continua sendo sua responsabilidade.iii Por isto, a necessidade de estudar e lutar pela igualdade de gênero, combater a cultura do assédio, na qual a mulher é submetida em casa, no trabalho, na rua, nos mais diversos ambientes, tem caráter emergente. Se considerarmos a desigualdade racial, a discrepância dos dados é ainda maior, pois as mulheres são duplamente discriminadas e esses fatos refletem profundamente no estilo de vida delas.

Segundo pesquisa desenvolvida pelo Ministério do Trabalho e Previdência Social em parceria com o Instituto de Pesquisa Econômica Aplicada (IPEA), de 2016, 39,6\% das mulheres negras estão inseridas em relações precárias de trabalho, seguidas pelos homens negros $(31,6 \%)$, mulheres brancas $(26,9 \%)$ e homens brancos $(20,6 \%)$. Ainda segundo a pesquisa, mulheres negras eram o maior contingente de pessoas desempregadas e no trabalho doméstico (RIBEIRO, 2017, p. 40).

À medida em que a pesquisa foi se corporificando, compreendemos os diferentes tipos de opressões vividos pelas mulheres, pois elas contam com particularidades que divergem entre si. Refletimos a intersecção de opressões, tirando o olhar do individual para o coletivo, e por meio desse "olhar para o outro", a pesquisa se constitui, assumindo as particularidades e questionando o universalismo da mulher branca, entendendo as 
diferenças entre elas. Os meios digitais propiciam espaço de debate para mulheres, negros, pessoas em situação de rua, indígenas, ciganos, entre outros grupos que se sentem oprimidos e sem lugar de fala nos ambientes de privilégio, como as instituições. "O espaço virtual tem sido um espaço de disputas de narrativas, pessoas de grupos historicamente discriminados encontram aí um lugar de existir" (RIBEIRO, 2017, p. 86).

A internet tem um efeito viral, que espalha de forma muito veloz os dados postados e é então que esses movimentos ganham voz, espaço e, consequentemente, força na sociedade. Com a facilidade de propagação desse discurso, as manifestações tomam formas e refletem no ambiente off-line, como nas ruas, por meio de manifestações, reivindicações, entre outros.

O que confere força a um movimento social muitas vezes está ligado aos aspectos relacionados à emoção, que faz com que os indivíduos se liguem entre si através da comunicação. "A construção de significados na mente das pessoas é uma fonte de poder mais decisiva e estável. A forma como as pessoas pensam determina o destino de instituições, normas e valores sobre os quais a sociedade é organizada" (CASTELLS, 2017, p. 20). A rede on-line permite que milhares de pessoas se conectem por um mesmo vínculo, o que faz com que se espalhem muito rapidamente os dados ou discursos presentes no ambiente virtual.

\section{Metodologia de pesquisa}

Os objetos discursivos que fazem parte do corpus dessa pesquisa são 02 (duas) páginas on-line do Facebook: Djamila Ribeiro ${ }^{\text {iv }}$, filósofa, feminista, engajada nos estudos das relações raciais, e Márcia Tiburi ${ }^{\vee}$, filósofa, escritora, professora e ativista política. 
Trata-se de personagens públicas de grande visibilidade e que se declaram feministas. Com relevante número de seguidores, a primeira conta com um total de 144.061 (cento e quarenta e quatro mil, sessenta e uma) pessoas que acompanham suas publicações, e a segunda, 114.683 (cento e quatorze mil, seiscentos e oitenta e três). Reconhecemos que o discurso delas, de alguma forma, pode vir a causar efeitos nos interlocutores que acompanham suas publicações nos suportes midiáticos. Esta pesquisa é de cunho qualitativo e documental.

A pergunta que norteia essa pesquisa é: Por meio de quais estratégias discursivas se constrói o ethos feminino no veículo midiático selecionado? Como recorte temporal, propomos analisar as postagens com mais reações de audiência pública manifestadas através de curtidas ou compartilhamentos no período de 06 (seis) meses, de 01 de julho a 31 de dezembro de 2017, sendo selecionadas 04 (quatro) postagens de cada mês. 0 conteúdo é ora reproduzido por meio de capturas de tela.

\section{Análises dos sujeitos discursivos}

\subsection{A imagem de Márcia Tiburi na plataforma on-line Facebook}

Márcia Tiburi é filósofa, professora e escritora. Observamos a seguir o trecho da apresentação da autora em sua página inicial do Facebook, na seção denominada História.

Figura 01 - Trecho do perfil de Márcia Tiburi no Facebook 


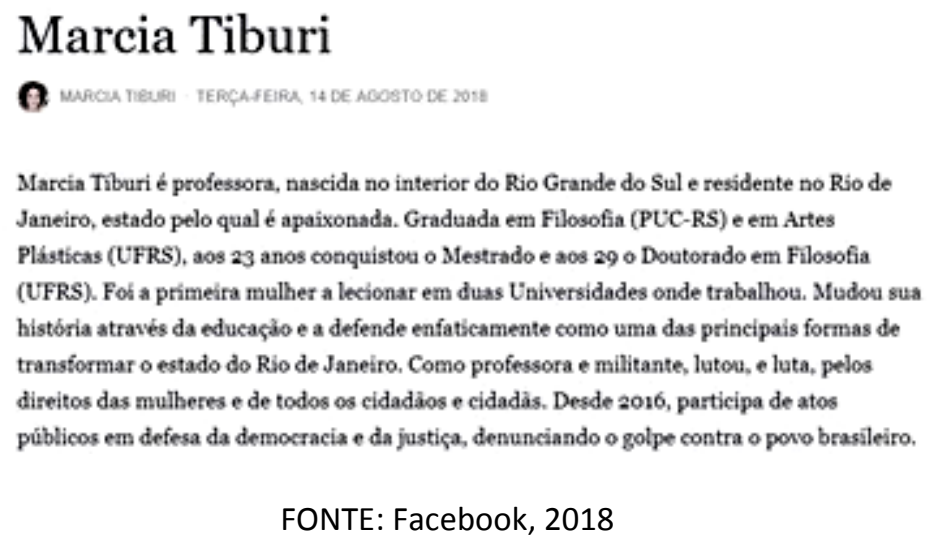

A filósofa se vale da estratégia de falar bem de si para reforçar uma imagem positiva, baseada em valores sociais considerados dignos. Para colaborar na construção de sua credibilidade, a autora descreve sua trajetória, em terceira pessoa. Essa imagem é estabelecida a partir de valores como justiça e igualdade. Nessa descrição, Márcia Tiburi está relacionada aos substantivos professora, escritora e militante. Muito recorrente no excerto acima, o verbo lutar aparece acompanhado de outros verbos de ação, dos quais ela própria é agente. Notamos, a todo momento, a intenção de trazer ao/à leitor/a a ideia de mulher ativa. Primeiro ao conquistar o mestrado e o doutorado, em seguida por quebrar padrões, ao ser a primeira mulher a lecionar em duas universidades. Essa forma de adjetivação auto elogiosa é usada como estratégia de ênfase da informação, destacando tratar-se de uma mulher que se afirma como sujeito que rompeu com os estereótipos tradicionais associados ao lugar da mulher. Apesar de explicitar lutar pelos direitos das mulheres ela não usa o termo feminista. Seu texto desnaturaliza esta concepção engessada de mulher frágil e submissa, e imprime uma noção de mulher empoderada, protagonista de sua própria história.

Em suas postagens, a autora opta pelo discurso direto, escrevendo de forma sucinta e com legendas curtas. As publicações são exclusivamente relacionadas ao âmbito 
profissional e não fazem referência à sua vida pessoal. Deste modo, Márcia desestabiliza uma feminilidade tradicional, tensiona a concepção de que à mulher estão destinadas as questões do lar, privadas, íntimas e subjetivas. Ao privilegiar representações de si que contemplam sua vida profissional, a filósofa destaca o âmbito público, objetivo, social.

A atitude de Tiburi de vincular conteúdo composto por informações completas sobre como obter o livro que divulga, onde encontrar determinado artigo ou assistir à palestra em questão, também demonstra sua intenção de mostrar-se empoderada. A filósofa evidencia também se preocupar com as dúvidas sobre seus textos ou aulas por parte de seus interlocutores:

Figura 02 - Publicação de Márcia Tiburi em 06 de julho de 2017

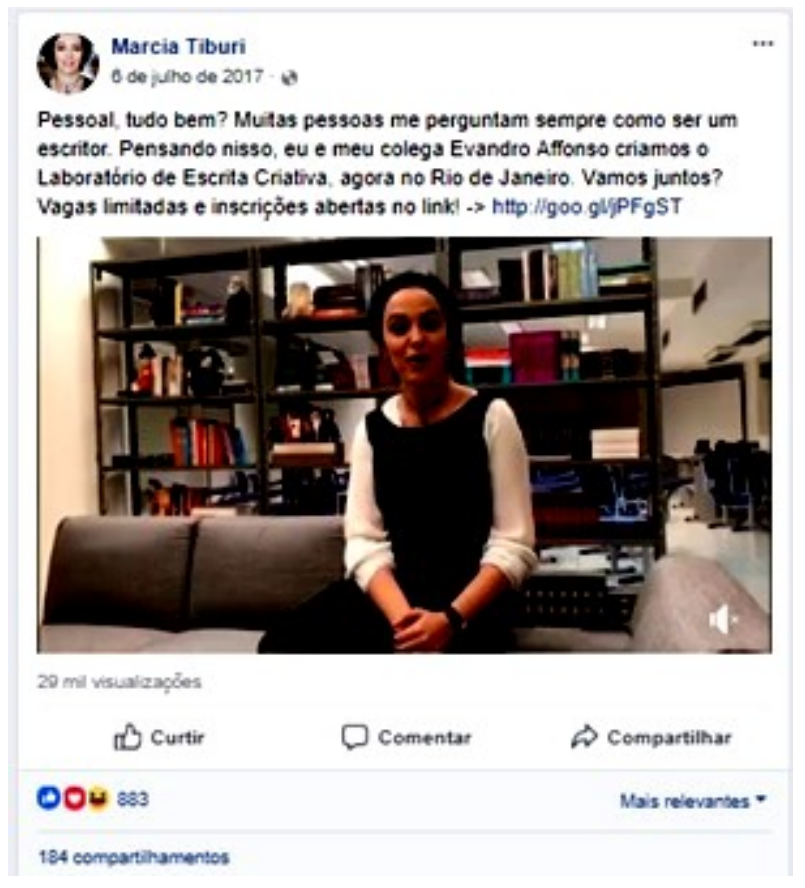

FONTE: Facebook, 2017

No trecho anterior, a autora cria um alinhamento com sua audiência, verificado ao observar a abordagem que faz em "Pessoal, tudo bem?". A escritora se mostra 
comprometida e preocupada com as questões levantadas por seus leitores. Percebe-se isso com o uso da expressão "pensando nisso". Ela age "respondendo algumas questões" dos interessados nos assuntos propostos, o que resulta na construção do ethos de credibilidade em relação ao seu trabalho. Atrelado ao ethos de credibilidade, observa-se o ethos de expert, pois "muitas pessoas" a questionam sobre ser um escritor. A filósofa se vale de estratégias discursivas como informações enciclopédicas para conferir um viés de credibilidade e legitimidade aos seus discursos.

A eficiência, a seriedade, o comprometimento, a credibilidade que emergem nos excertos anteriores refletem caraterísticas profissionais que são, hegemonicamente, esperadas de homens. Nesses excertos, a autora busca construir um ethos de seriedade (Cf. CHARAUDEAU, 2013) e competência e um pathos de confiança e persuasão no leitor.

Figura 03 - Publicação de Márcia Tiburi em 18 de agosto de 2017

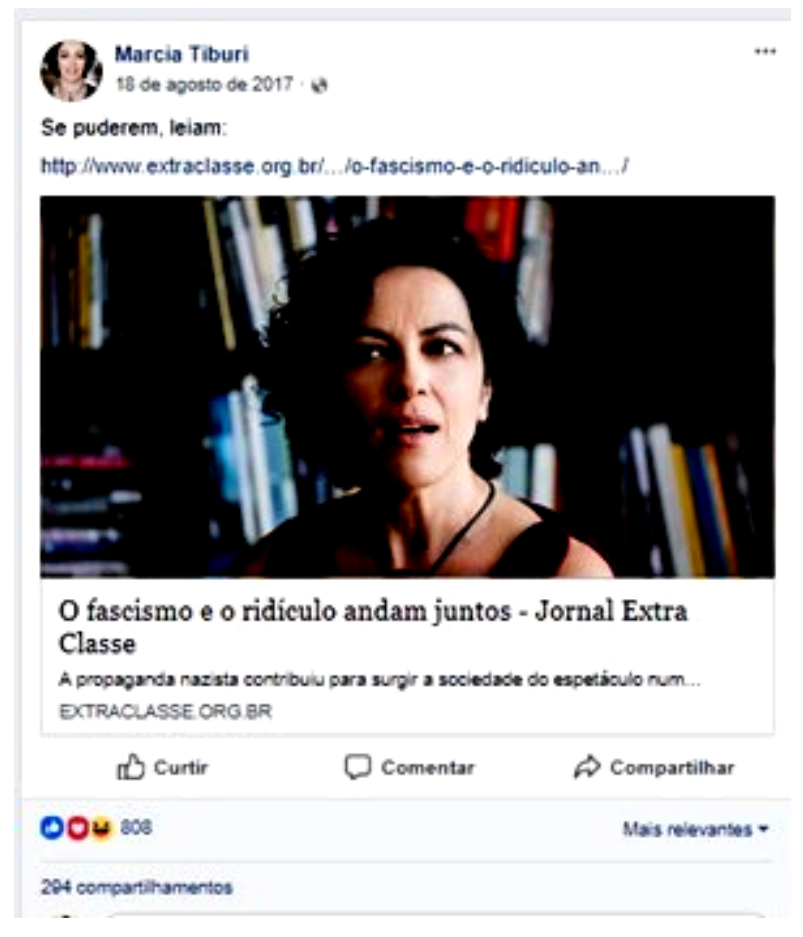

FONTE: Facebook, 2018.

Figura 04 -Publicação de Márcia Tiburi em 04 de setembro de 2017 


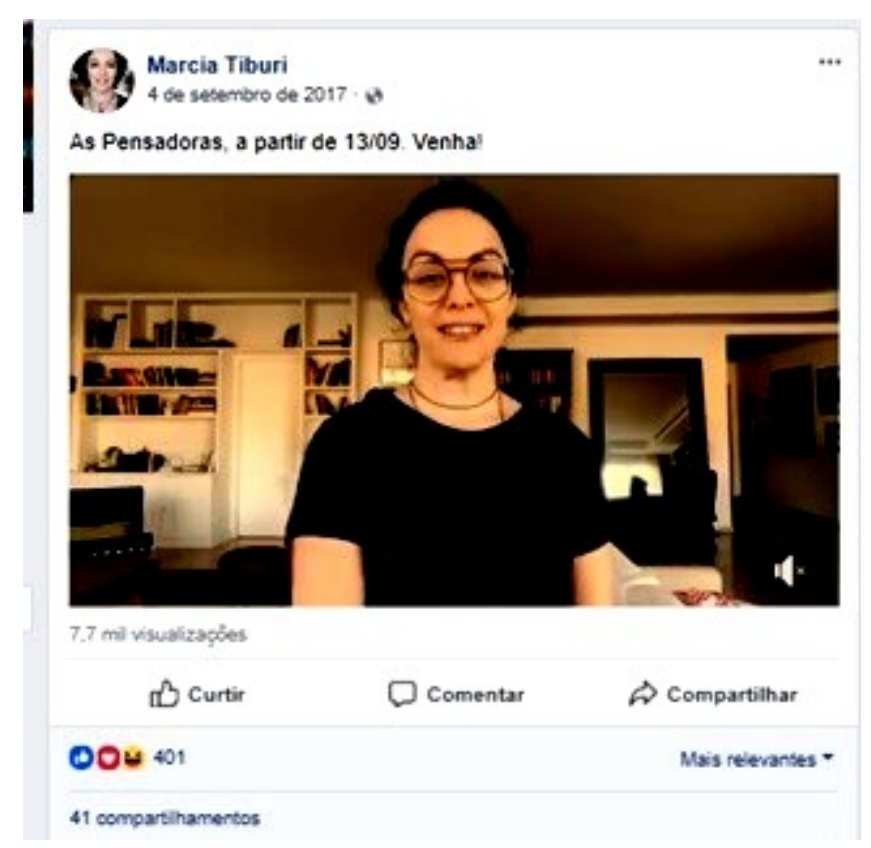

FONTE: Facebook, 2018

Através do uso das formas verbais ler e vir no excerto acima, Márcia Tiburi convida a todos que a acompanham nas redes sociais a participarem de seus cursos e palestras. Os verbos imperativos também ajudam a construir um ethos que diverge do estereótipo da mulher "recatada" ou "calada". A escolha dos verbos ler e vir são convites aos leitores que se interessam pelas temáticas abordadas para que possam ter acesso ao local ou site divulgados. Acreditamos que ao incluir o leitor, o efeito de alinhamento vai além de causar empatia; ele representa o posicionamento de uma pessoa privilegiada, uma vez que Marcia é professora universitária que detém o título de doutora em um país de educação tão precária e com números de analfabetismo ainda bastante altos. Ela busca demonstrar a intenção de colocar-se à disposição, criando uma tendência ao diálogo, e, portanto, diminuindo a diferença social e acadêmica que se coloca entre ela e seus possíveis leitores. 
Observe que a autora usa também a expressão "se puderem", a modalização auxilia na criação desse alinhamento, a construção indica que há uma empatia de Márcia para com seus leitores, que têm as mais diversas realidades; há uma ideia de partilha, e não de imposição, que denotaria uma relação desigual de poder.

O discurso em primeira pessoa é característico desse gênero textual e a escritora, além de fazer uso do comportamento elocutivo, faz uso frequente do pronome possessivo "meu":

Figura 05 - Publicação de Márcia Tiburi em 12 de dezembro de 2017

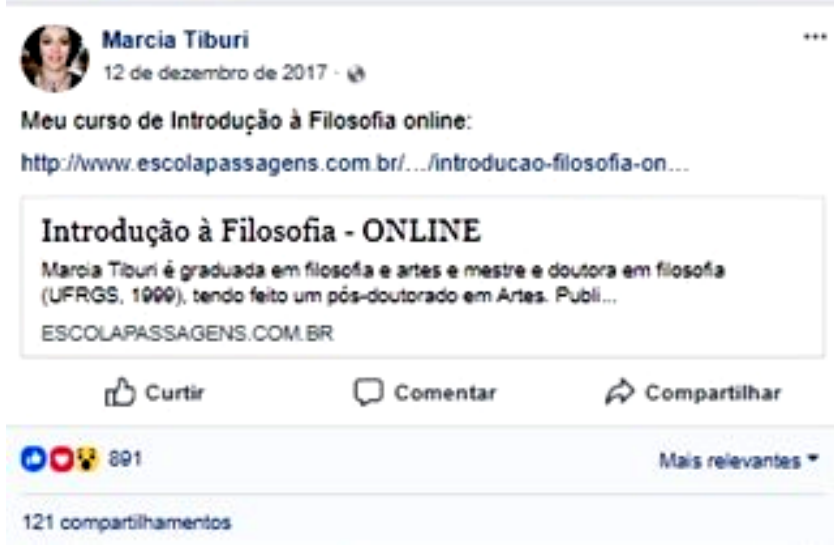

FONTE: Facebook, 2018

Interessante notar que surte algum efeito no/a interlocutor/a a menção de que o curso será ministrado pela filósofa, pois o número de curtidas e compartilhamentos é relevante, o que faz com que essa postagem atinja um número ainda maior de pessoas.

O que predomina na página de Tiburi são postagens a respeito de cursos de filosofia, artigos e livros, o que nos leva a reforçar o ethos de expert já exemplificado. A profissional em questão mostra-se especialista na área a qual se dedica. Sua fala representa seu papel social de professora e filósofa que, através de seus textos, "luta" 
contra estruturas sociais enrijecidas. Ela ainda reforça a figura de profissional competente, quando se mostra ciente dos assuntos da atualidade.

\subsection{A imagem de Djamila Ribeiro na plataforma on-line Facebook}

Djamila Ribeiro é filósofa, feminista e engajada nos estudos do feminismo negro. Ao contrário de Márcia Tiburi, na página pessoal de Djamila Ribeiro não consta a seção denominada "História". Suas postagens se concentram nos âmbitos pessoal e profissional. Em análise, percebemos que, embora o aspecto pessoal não predomine em sua página, é recorrente. As duas mulheres analisadas se dissociam das representações sociais partilhadas e do estereótipo criado para a mulher como sendo ligada apenas ao ambiente doméstico. Elas mostram-se empoderadas e se destacam no âmbito público e social, espaços que não seriam destinados a elas.

O uso do pronome pessoal "eu" e o pronome possessivo "meu" são bastante frequentes, e acredita-se que, neste contexto, isso seja significativo: 
Figura 06 - Publicação de Djamila Ribeiro em 04 de outubro de 2017

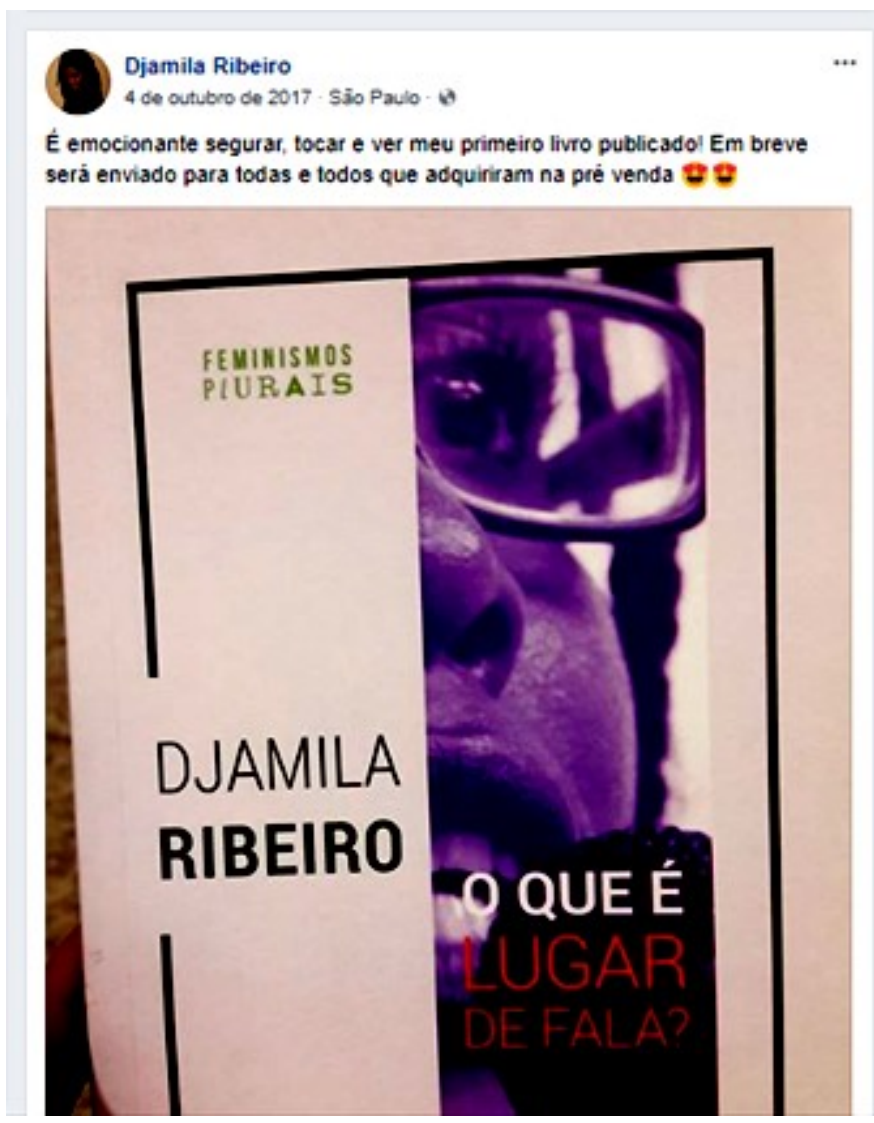

FONTE: Facebook, 2018

Historicamente, as mulheres eram proibidas de escrever, $\mathrm{O}$ fato de elas assumirem a autoria de suas obras é empoderador e relevante na vida das mulheres, que podem ter seus trabalhos reconhecidos. Isso é observado, em especial, no caso de Djamila, mulher e negra, duplamente discriminada em uma sociedade historicamente racista.

A trajetória e a visibilidade de Djamila são percebidas como conquista por parte das pessoas de origem negra, representando anos de luta por direitos iguais e visibilidade da cultura negra. Ao conquistar seu lugar de fala, ela propicia que muitas jovens possam conquistar o seu também, ou saber que aquele é um lugar possível para elas. Seus 
interlocutores se sentem representados nos discursos, ao passo que a autora constrói o pathos de confiança e persuasão nos seus leitores.

No discurso de Djamila, há trechos que descrevem sua trajetória de vida e, frequentemente, desconstroem a ideia da mulher frágil, remodelando esse perfil:

Figuras 07 - Publicação de Djamila Ribeiro em 11 de julho 2017

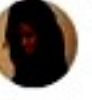
Djamila Ribeiro

11 de juho de 2017 : São Paulo - O

Facebook me lembrou que há três anos eu publicava meu primeiro texto na Carta Capital. Eu tinha 33 anos, estava no mestrado, escrevia para 0 Blogueiras Negras, havia sido coordenadora de núcleo da Educafro, trabalhado na Casa de Cultura da Mulher Negra, na Liga dos Amigos e Estudantes Africanos. Já era mãe, mas já não tinha a presença física de mãe e pai, que foram para o Orun em 2001 e 2002, respectivamente. Era casada, equilibrava os estudos com a vida em casa, tinha bolsa da Fapesp e havia, junto com outros colegas, fundado o Mapô- Núcleo de Estudos Interdisciplinar em Raça, Gènero e Sexualidade da Unifesp. Já havia sido professora de filosofia em uma escola estadual da periferia de Guarulhos e trabalhado como auxiliar de serviços gerais. Havia participado de 3 conferências internacionais e lavado chăo de CA pra fazer eventos.

FONTE: Facebook, 2018

Figuras 08 - Publicação de Djamila Ribeiro em 11 de julho 2017

Djamila Ribeiro

11 de juho de 2017 - Săo Paulo - O

Facebook me lembrou que há três anos eu publicava meu primeiro texto na Carta Capital. Eu tinha 33 anos, estava no mestrado, escrevia para o Blogueiras Negras, havia sido coordenadora de núcleo da Educafro. trabalhado na Casa de Cultura da Mulher Negra, na Liga dos Amigos e Estudantes Africanos. Já era mãe, mas já não tinha a presença física de mãe e pai, que foram para o Orun em 2001 e 2002, respectivamente. Era casada, equilibrava os estudos com a vida em casa, tinha bolsa ... Ver mais

$\mathbb{3}$ Curtir $\Rightarrow$ Compartilhar 
FONTE: Facebook, 2018

Nesse último trecho, nota-se a importância do enunciado para a construção da força argumentativa de sua imagem: a de alguém com atitudes proativas louváveis. 0 relato de vida, expresso pelo uso dos verbos no passado, revela estados e ações que projetam a imagem de uma pessoa honesta e trabalhadora. A escolha destes usos referese a imagem de alguém que luta pela justiça e igualdade de gênero nas relações sociais.

Identificamos que, no fragmento "que foram para Orun", a filósofa sinaliza sua orientação religiosa. Além do mais, ao fazer questão de destacar sua trajetória, a autora constrói uma imagem de alguém "transparente", que não tem nada a esconder, o que, consequentemente, colabora na construção de sua credibilidade diante do público.

No exemplo acima são destacados os diversos papeis representados socialmente por ela, como mãe, esposa, filha, escritora, estudante, coordenadora e professora. Tratase de papéis desempenhados que são socialmente impostos às mulheres que desejem ter uma vida profissional - no caso dela, professora - e não exclusivamente os afazeres domésticos que ainda hoje, na maioria dos casos, são responsabilidades da mulher.

Em outra passagem, é ressaltada uma condição de simplicidade pontuada pelo tom de denúncia de circunstâncias impostas pelo patriarcado: 
Figura 09 - Publicação de Djamila Ribeiro em 24 de dezembro de 2017

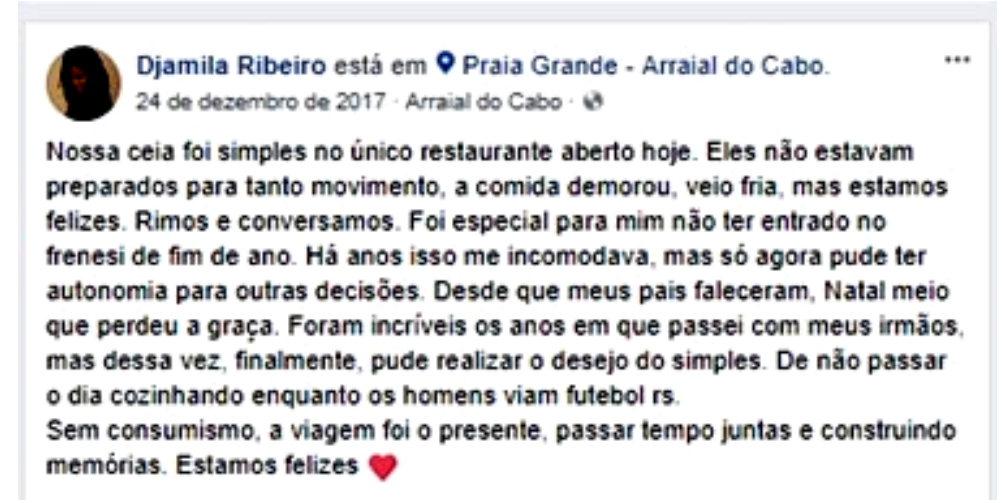

FONTE: Facebook, 2018

O excerto "[...] de não passar o dia cozinhando enquanto os homens viam futebol rs," expressa uma atitude crítica da enunciadora em relação a um estereótipo social relacionada ao papel da mulher, presente não somente no lar de Djamila, mas de muitas mulheres brasileiras. Esse estereótipo relaciona-se ao cenário das mulheres trabalhando, cozinhando e organizando a casa para a ceia de Natal. O que a análise aponta é que a ceia, na maioria das vezes, é de responsabilidade feminina. Entretanto, esse cenário não é característico apenas da data, mas recorrente durante todos os outros dias do ano, pois são milhares de horas que as mulheres dedicam por ano nas atividades domésticas ${ }^{\mathrm{vi}}$. Além do mais, o trabalho doméstico, além de ser árduo, repetitivo, desvalorizado foi e ainda é comumente destinado a elas. No sistema capitalista que visa o lucro, o trabalho doméstico não remunerado e nem reconhecido.

O ethos mais representativo de todo o corpus da página do Facebook de Djamila Ribeiro foi o de militância nas causas do feminismo negro e da luta contra o racismo. Por meio das análises, percebemos que a luta pelo povo negro é marcada em seu discurso. 
Seus argumentos são acompanhados de fatos históricos que comprovam seu ponto de vista, questionando a estrutura social estabelecida e fornecendo credibilidade à imagem que procura passar:

Figuras 10 - Publicação de Djamila Ribeiro em 14 de agosto de 2017

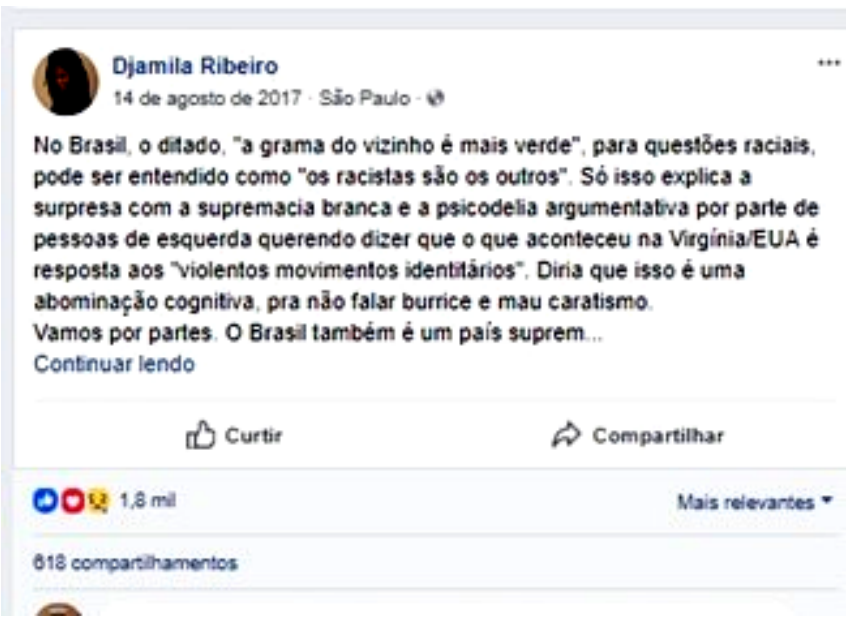

FONTE: Facebook, 2018

Figuras 11 - Publicação de Djamila Ribeiro em 14 de agosto de 2017

\begin{abstract}
No Brasil, o ditado, "a grama do vizinho é mais verde", para questões raciais, pode ser entendido como "os racistas são os outros". Só isso explica a surpresa com a supremacia branca e a psicodelia argumentativa por parte de pessoas de esquerda querendo dizer que o que aconteceu na Virginia/EUA é resposta aos "violentos movimentos identitários". Diria que isso é uma abominação cognitiva, pra não falar burrice e mau caratismo. Vamos por partes. O Brasil também é um pais supremacista branco no que diz respeito a poder. Existe uma supremacia branca no judiciário, nos altos escalōes das empresas, na política institucional, nas universidades públicas. no poderio das midias, enfim, nos espaços de poder. Ao passo que a população negra é marginalizada, a cada 23 minutos um jovem negro é assassinado e nos últimos 10 anos aumentou em $54,8 \%$ o assassinato de mulheres negras, só para dar alguns exemplos.
\end{abstract}

FONTE: Facebook, 2018

Fazendo uso de estratégias discursivas que apresentam informações e dados estatísticos, a autora conjuga o ethos de militante com o de expert. Por meio destes, a autora constrói um argumento persuasivo com base na identidade negra e na 
credibilidade acadêmica do seu discurso, valendo-se do conhecimento que é mostrado em sua fala. Sua opinião é embasada em dados e fatos, como neste último exemplo. Os dados contribuem para construção de um ethos positivo em relação a imagem que a autora deseja passar.

Observamos que as autoras, a partir das perspectivas experienciais, "lutam" contra estruturas sociais enrijecidas que colaboram com discussões da atualidade. Márcia Tiburi se debruça sobre o feminismo e questões políticas e filosóficas e Djamila Ribeiro dedica-se ao feminismo negro. Em suma, essa construção de uma imagem positiva, percebida pelas suas particularidades discursivas, torna-se fundamental na construção de uma imagem como cidadã digna de crédito. Sem essa imagem de si, suas palavras estariam desprovidas de legitimidade e credibilidade diante do seu público. A legitimidade da imagem construída se efetiva pela credibilidade de suas ações.

\section{Considerações finais}

Concluímos que as autoras se utilizam das mídias on-line como ferramenta discursiva, objetivando o empoderamento das mulheres. É interessante notar que, de certa forma, elas se veem como portadoras de uma autoridade para aconselhar seus leitores. No perfil de Márcia Tiburi, percebemos que ela assume a responsabilidade de promover o acesso à informação. Já no perfil pessoal de Djamila Ribeiro, a autora assume uma postura de valorização das diferentes culturas. Por meio dos discursos analisados, percebemos que os sujeitos discursivos têm a intenção de provocar um efeito ou ação em seus interlocutores, a fim de modificar a noção de ethos coletivo. 
As análises apontaram ethé que correspondem nos dois perfis individuais considerados, como o ethos central de expert, resultando em imagens positivas de si, que se ressaltaram a construção discursiva de mulheres intelectuais. Em contraponto com o perfil de Márcia Tiburi, Djamila Ribeiro projeta o ethos de humanidade. O fato de a autora deixar transparecer seus sentimentos não interfere na credibilidade e legitimidade de seus discursos.

Foi comum nas análises a desconstrução do padrão hegemônico da mulher passiva, pois ela se destaca no âmbito público e social, rompendo com a oposição estereotipada que cerca as relações sexuais: homem/mulher, privado/público, poder/submissão. Elas constroem seus discursos com a intenção de quebrar o ethos coletivo que coloca as mulheres à margem do acesso à educação, do acesso ao trabalho e da ocupação de um espaço social e discursivo, construindo um ethos de mulheres empoderadas.

\section{Referências}

AMOSSY, Ruth. Imagens de si no discurso: a construção do ethos. São Paulo: Contexto, 2005.

. Imagens de si no discurso: a construção do ethos. 2. ed. São Paulo: Contexto, 2018.

BENVENISTE, Émile. A linguagem e a experiência humana. In: Problemas de linguística geral II. 2. ed. Campinas, SP: Pontes Editores, 2006.

BRANDÃO, Helena H. N. Introdução à análise do discurso. 2. ed. rev. Campinas, SP: Editora da Unicamp, 2014.

CASTELLS, Manuel. Redes de indignação e esperança: movimentos sociais na era da internet. 2. ed. Rio de Janeiro: Zahar, 2017. 
CHARAUDEAU, Patrick. Discurso político. 2. ed., 1a reimpr. São Paulo: Contexto, 2013.

CHARAUDEAU, Patrick. A conquista da opinião pública: como o discurso manipula as escolhas políticas. São Paulo: Contexto, 2016.

FIORIN, José L. Os fatores da argumentação. In: Argumentação. São Paulo: Contexto, 2015.

MAINGUENEAU, Dominique. Novas tendências em análise do discurso. 3. ed. Campinas, SP: Pontes, 1997.

RIBEIRO, Djamila. O que é: lugar de fala? Belo Horizonte: Letramentos, Justificando, 2017.

WODAK, R. Do que trata a ACD: um resumo de sua história, conceitos importantes e seus desenvolvimentos. Linguagem em (Dis)curso 4. Universidade do Sul de Santa Catarina, Santa Catarina, 2004.

Recebido em 26 de maio de 2019.

Aceite em 01 de agosto de 2019.

\footnotetext{
${ }^{1}$ Para percurso histórico do movimento social feminista especificamente no Brasil, ler: COSTA, Ana Alice Alcantara. O movimento feminista no Brasil: dinâmicas de uma intervenção política. Revista Gênero. 2005. Disponível em: http://www.revistagenero.uff.br/index.php/revistagenero/article/viewFile/380/285 Acesso em: 24 dez. 2018.

2 Disponível em: http://www.ebc.com.br/cidadania/2015/04/desigualdade-de-genero-no-mercado-detrabalho-persiste-diz-onu. Acesso em: 07 abr. 2018.

3 DAVIS, Angela. A obsolescência das tarefas domésticas se aproxima: uma perspectiva da classe trabalhadora. Disponível em: https://praxismagazine.org/2018/11/20/a-obsolescencia-das-tarefas-domesticas-se-aproximauma-perspectiva-da-classe-trabalhadora-angela-davis/. Acesso em: 20 nov. 2018.

${ }^{4}$ Disponível em: https://www.facebook.com/djamila.ribeiro.1

${ }^{5}$ Disponível em: https://www.facebook.com/MarciaTiburi/

${ }^{6}$ DAVIS, Angela. A obsolescência das tarefas domésticas se aproxima: uma perspectiva da classe trabalhadora. Disponível em: https://praxismagazine.org/2018/11/20/a-obsolescencia-das-tarefas-domesticas-se-aproximauma-perspectiva-da-classe-trabalhadora-angela-davis/. Acesso em: 20 nov. 2018.
} 